\title{
Countering Ideological Support for Extremism: Challenges and Implications
}

\author{
Carlton W. Fulford, Jr. *
}

We cannot win the war against terrorism if we do not understand and deal with its ideological dimension. Nor can the West do this alone. Following the attacks on 11 September 2001, one of the principal questions asked in the United States about the Muslim world—one that has not yet been answered to my knowledge—is, "Why do they hate us so much?" Perhaps a relevant corollary is, "Why have we become, or allowed ourselves to become, the primary target of extremists?" Attempts to deal with this aspect of the war on terrorism have taken several names: for example, "countering ideological support for extremism" and "strategic communication.” But to my knowledge we have not yet satisfactorily understood "why they hate us so much," and we still lack any effective strategy to deal with the issue of the ideology that motivates people to commit terrorist acts.

That is why this conference is so important. You know the tenor of public sentiment in your countries. You know how your citizens react to U.S. words and actions. We need to listen more before taking action. We also must realize that we are judged by what we do, not just by what we say.

Our military men and women have successfully pursued a dynamic response to acts of terror. Each American looks with pride at the professionalism and sacrifice of our servicemen and -women in doing what soldiers should do-killing the bad guys and winning our nation's wars. The non-kinetic aspect of the war on terror has proven to be a much more difficult task, and is clearly one in which soldiers, sailors, airmen, and marines can assist, but they cannot accomplish it alone.

Conferences like this promote knowledge and understanding, both of which are in sadly short supply. In the absence of knowledge and understanding, suspicion and misunderstanding take root. I firmly believe these two evils-suspicion and misunderstanding - are at the foundation of the hatred that exists in the Muslim world toward the West in general, and the United States in particular.

We must also admit, however, that legitimate and sometimes contradictory national interests play a role in generating these conflicts, as does the manner in which different nations pursue these interests. We must learn about each other, recognize real divergences of interests, and manage them vigorously in order to avoid further polarization of disputes. The stakes involved in this dynamic are incredibly high and, to be sure, disengagement-letting parts of this world go down their own paths, or blithely hoping that they can exist in their own isolation-is simply not a possibility. Globalization is

General Carlton W. Fulford, Jr., USMC (Ret.) is the Director of the Africa Center for Strategic Studies at the National Defense University in Washington, D.C. This paper is drawn from his keynote address at the conference Countering Ideological Support for Terrorism: Opportunities and Limitations in the Battle of Ideas, Garmisch-Partenkirchen, Germany, 17-21 July 2006. 
here to stay. It is not going away, and we must learn how to deal with it. Many communities in our world are intricately connected, and each needs the other: for our security, our prosperity, and our future. Islamic extremists who seek to reestablish the caliphate and return to the purity of the first generation of Islam cannot succeed. Likewise, the global society in which we live has taught the United States that we cannot simply ignore the aspirations of the millions of people-most of whom are peaceable and tolerant-who make up the Muslim world. Better understanding will help, but concrete steps are more important at this stage, because Islamist extremists have focused their attention on Western "double standards," to which we must respond through actions, not words.

Everybody can help define the actions that will be most useful in their part of the world. Since retiring from active military service, I have focused my attention on Africa—and much of this essay derives from that focus. Over 400 million Muslims live in Africa. Several African nations have Muslim populations greater than any nation in the Middle East. Most seek to live their lives with a sense of decency and dignity, though many must struggle with the basic elements of daily survival. Sufi Muslim thought has been studied, taught, and practiced for centuries in places like Timbuktu, Mali. However, political Islam-springing from the Muslim Brotherhood in Egypt and, more recently, from Wahabbist/Salafist teaching from the Arabian Peninsula-is spreading through the Horn and Saharan Africa.

Islam is growing rapidly in Africa. Muslim charities offer much-needed help in many areas of conflict and immense poverty. Mosques are being built and jobs are being created in South Africa. Leaders in many African nations, however, are concerned about extremist messages coming into their Muslim communities from outside Africa.

This has made Africa a frontline battlefield in the Islamist struggle. Today, progressive Muslims remain in control in most African states. Anti-Americanism is not rampant, though skepticism and a lack of trust toward the U.S. exists. In Africa, as in other places around the world, we need to understand perceptions (even though they might be false) and take appropriate steps to create understanding and foster tolerance.

\section{Perceptions of the West}

U.S. global relations, and particularly our relations with the Muslim world, cannot be understood without acknowledging the impact of both the Israeli-Palestinian conflict and the conflict in Iraq. Unfortunately, these are perceived in many quarters of the world-including Africa-as evidence of U.S. imperialism and a "war on Islam.” We can point to a long history of the U.S. coming to the aid of Muslims around the world: in the Middle East, in Kuwait, in Bosnia and Kosovo, just to name a few recent examples. I personally participated in the evacuation of Yassir Arafat and the PLO from Beirut in the early 1980s, just as General Sharon was about to obliterate them. Despite these examples, most observers in the Muslim world see the U.S. as the "unconditional protector" of Israel. They also believe that the United States is the world's one true superpower, and if it wanted to do something, whatever it might be, the U.S. could do it. Most Americans, on the other hand, acknowledge that there are limitations to U.S. power, and most see our actions as designed to defend U.S. national interests and pro- 
mote freedom and democracy-which is in the best interests of everyone in the world. That is the foundation for support of our actions in Iraq.

Many communities around the world interpret U.S. actions very differently. First of all, and perhaps most importantly, they believe the U.S. could resolve the Israeli-Palestinian crisis if we tried. Similarly, although most people around the world understood our reaction to 9/11 in Afghanistan-despite questioning the proportionality-global sentiment has been generally against our actions in Iraq.

Disclosures-no matter how real or sensationalized - of U.S. torture, atrocities, lack of due process, renditions to "black site" prisons, etc., have seriously damaged the United States' image as the shining example of a "city on a hill.” On the contrary, they have fostered the notion that the U.S. flouts international law when it suits its purposes, and is focused only on its own selfish interests. U.S. support for corrupt, authoritarian, or cruel governments and leaders further erodes the notion of the United States as a "shining example" for the rest of the world, and opens the U.S. to the criticism of operating under a double standard. Nigerian Islamists point to their nation's endemic corruption as a result of the evils of capitalism, and condemn their corrupt political leaders as puppets of the West. When millions live on the knife's edge of survival from one day to the next and there is no sense of hope while Western affluence appears to increase by the day, it is not difficult to offer an argument that blames their impoverished condition on Western conspiracies.

Another element of the Muslim world's view toward the United States is cultural, rather than political or economic. U.S. popular culture is both loved and hated beyond our borders. Having lived in various parts of the world, it is interesting to observe the gap between how we see ourselves and how people in other parts of the world view us. Europeans still see us as naïve and politically immature. They recognize our strength, but still feel compelled (and entitled) to advise us on how to use that strength. In Asia and the Middle East, satellite television networks beam reruns of "Dallas" and "Baywatch" to millions of viewers, who think that these shows really represent U.S. culture. The Muslim world has the perception that the United States in particular, and the West in general, harbor societies with little attachment to religious values-Christian or otherwise - and that we are marked by a moral decay that we are spreading around the world. I read or hear little about how U.S. values served to make this nation the world's sole superpower. The feeling is that we are a superpower because we are rich-without any discussion as to how we became rich-and that we are using our military and economic power to impose our tainted values on the rest of the world.

Finally, many citizens in Africa and the Middle East-Muslims and non-Muslims alike-think that U.S. policy toward their countries is driven overwhelmingly by one specific interest: oil, and particularly the use of oil to maintain and expand our world dominance. We can debate the validity of this perception, but we cannot afford to doubt the fact that it is a widely held belief.

These perceptions, false though they may be, are used daily to build support for jihad against the "Great Satan" as the appropriate strategy to address local conditions of economic deprivation and political marginalization in the Middle East. We must endeavor to show—and, as I said earlier, demonstrate our conviction through actions, not 
only words - that these perceptions describe neither the United States of America nor the values we stand behind. We are predominantly a Christian nation, but we must demonstrate that we are tolerant of all faiths, judgmental of none, and truly believe in "one nation, under God, with liberty and justice for all."

I will conclude with a number of recommendations for U.S. strategy and policy that I believe must be undertaken simultaneously in order to repair relations between the United States and the Muslim world, as well as to effectively counter the very real threats posed by Islamist extremism to both U.S. and global security.

First, I believe we must elevate our thinking and our actions to describe and alleviate the root causes of extremism and the permissive factors that enable terrorists to operate and mobilize support. We clearly must do all we can to disrupt terrorist operations that threaten our nation; we must kill or capture extremists perpetrating terrorist acts. But we must also guard against actions that will create further grievances that can motivate new waves of resentment and future generations of terrorists. Events that are currently unfolding in the Middle East could have grave implications for our ability to counter ideological support for extremism.

We must also carefully assess the importance and limitations of U.S. cooperation efforts with other nations in solving the challenge of Islamist extremism, many of which are at the same time part of the problem. Once we burnish our own credibility, we must set the bar high for our alliance partners. We need to take visible action that demonstrates the values of the United States. What the Western world did in Bandar Aceh or Palestine silences fanatics, and shows the world that we are a compassionate nation and we care about our fellow human beings. Our actions can produce a tangible impact on issues that matter the most in the day-to-day lives and beliefs of Muslim communities. I would propose that we take a hard look at increasing foreign development aid, especially aid that is focused on educational systems in poor or developing nations.

I believe that open and honest dialogue regarding strategic interests is much more effective than "information warfare" or "strategic communications." To be absolutely frank, many in the world simply do not believe what the United States says any more, and when you couple this with the rhetoric of extremists who amplify issues or misrepresent what we do or say, we have a problem. We collectively must work to restore our moral values in the eyes of the world. This can be done through honest and open dialogue, which means that we listen as well as talk.

By any measure, 9/11 was a tragedy. Visiting Grosvenor Square in London and seeing the U.S. Embassy barricaded like a nineteenth-century Fort Apache is also tragic. The fact that there are men and women around the world who are convinced that their only hope is to blow themselves to pieces and take as many "infidels" with them as possible is tragic. The fact that my and your grandchildren will inherit a more dangerous world than we inhabited is tragic. The United States must rediscover its vision and communicate that vision around the world through our actions. Conferences such as this are clearly a significant step in that direction. Education, understanding, frank honesty, and tolerance will go a long way toward countering extremism and restoring peace and dignity to our troubled world. 